\title{
Designing Accreditation Standards for Limited Surgery Facilities in
}

\section{Iran}

\author{
Nader Asgari ${ }^{1}$, Somayeh Hessam (iD ${ }^{1,}$, , Iravan Masoudi Asl ${ }^{2}$ and Shaghayegh Vahdat ${ }^{1}$ \\ ${ }^{1}$ Department of Health Services Management, South Tehran Branch, Islamic Azad University, Tehran, Iran \\ ${ }^{2}$ Department of Health Services Management, School of Management and Information, Iran University of Medical Sciences, Tehran, Iran \\ "Corresponding author: Department of Health Services Management, South Tehran Branch, Islamic Azad University, Tehran, Iran. Tel: +98-9122268534, Email: \\ somayehh59@yahoo.com
}

Received 2019 November 05; Revised 2020 July 04; Accepted 2020 July 24.

\begin{abstract}
Background: Accreditation is the most powerful evaluation tool to validate a health care organization's attainment of standards set by an external peer review team.

Objectives: This study was done to identify and develop a comprehensive framework of standards affecting the performance of limited surgery centers.

Methods: This mixed-method study was conducted in 2019. Twenty experts were selected by the snowball sampling method. Initially, the basic concepts of criteria were designed according to the result of expert interviews. Then, 20 experts were asked to rate the importance of each criterion qualitatively based on a 5-point Likert scale from highly important to unimportant. Experts' opinions were inquired in three stages, followed by rating and determining the content impact of the extracted standards using the DEMATEL method.

Results: The conceptual model and then the initial model were designed. The basic conceptual model was identified in three main domains of patient safety, clinical care, and management and leadership. The highest weight was related to "safe discharge and follow-up of the patient", which gained the first priority. "Prevention and management of common surgical complications", "infection prevention", “continuing post-surgical care”, "imidate and emergency care”, and "surgical and anesthesia care" had the second to sixth priority among the ten subfactors, respectively.

Conclusions: According to our findings, the formulation of the standards of the limited surgical centers should be more focused on the safety and management of surgical complications.
\end{abstract}

Keywords: Limited Surgery Center, Accreditation, Standards

\section{Background}

The responsibility of governments for community health oblige them to develop an effective system responsive to health needs. Reinforcing the evaluation schemes of the health system is one of the essential measures in this field (1). In today's competitive environment, an appraisal system of performance and quality to promote growth and sustainability has become inevitable for all public and private organizations (2). Accreditation is the most powerful control and assessment tool to achieve the mentioned goals, which is described through the approval of a health care organization for meeting predetermined standards by an external peer-review team independent of the same organizational level (3) as well as its qualification by homogeneous trained groups based on the realization of minimum standards. Accreditation also provides a framework to create and implement systems and processes that improve operational effectiveness and advance positive health outcomes (4). Nowadays, policymakers of the health system have focused on improving the hospital indicators, mainly quality (5).

Several studies have been conducted on the effect of accreditation standards regarding the delivery of health care services, indicating that accreditation is a process that continuously improves the quality of service and performance, and develops positive health outcomes (4, 6-13). Various investigations have also shown that accreditation could lead to the improvement of quality indicators in limited surgery facilities. In 2008, Menachemi et al. (14) conducted a study in the USA to assess the quality of healthcare services on a total of 364 accredited and nonaccredited limited surgery facilities. Their results showed that in the case of a colonoscopy, no shorter hospital stay was an- 
ticipated in Joint Commission on Accreditation of Healthcare Organizations (JCAHO) accredited facilities relative to nonaccredited facilities because there were 30 days $(1.83 \%$ vs. $1.96 \%$ ) and $<7$ days (0.61\% vs. $0.63 \%$ ) of hospital stay, respectively. In the case of patients with cataract, the hospital stay $<30$ days in Joint Commission International (JCI)-accredited patients was less than unaccredited centers (1.13\% vs. $1.25 \%)$ (14). Similar results were reported by Behera et al. on a study, in which although the image quality and diagnostic accuracy did not differ significantly before and after accreditation, study comprehensiveness and report completeness improved after accreditation (12).

Similar to independent and supplementary institutions, limited surgery facilities in Iran lack proprietary or local quality standards. A limited and ambulatory surgery facility is defined as an institution, at which the patient could be discharged within a few hours $(<24 \mathrm{~h})$ after surgery (15). Although there are over 110,000 active medical institutions throughout Iran, which should offer service according to quality standards and specific criteria, there are no standard measures for limited surgery facilities in Iran. Therefore, considering the importance of quality control for limited surgery facilities in surgical interventions, high costs of operations, and a large number of patients and clients, designing an accreditation model to ensure the quality of performance of these facilities is important (16).

\section{Objectives}

Few studies on the accreditation of limited surgery facilities in Iran have been conducted. Therefore, this study was done to identify and formulate a general content framework of standards affecting the performance of limited surgery facilities using operation research models as well as reviewing experts' opinions in this area. Here, we used the fuzzy DEMATEL technique to rank and weight standards of limited surgery facilities.

\section{Methods}

This mixed-method study was conducted on 20 policymakers and accreditation experts that were selected by the snowball method (Table 1).

The main concepts of criteria were the designed qualitative expert interviews assessing the standards related to limited surgery facilities (the first questionnaire, including four questions). The experts were then requested to qualitatively rate the importance of each criterion based on a 5-point Likert scale from highly important to unimportant. The research background included:

\begin{tabular}{|c|c|}
\hline Experts' Characteristics & Values \\
\hline \multicolumn{2}{|l|}{ Position } \\
\hline Policymaker & $8(40)$ \\
\hline Accreditation experts & $12(60)$ \\
\hline \multicolumn{2}{|l|}{ Sex } \\
\hline Male & $7(35)$ \\
\hline Female & $13(65)$ \\
\hline \multicolumn{2}{|l|}{ Academic degree } \\
\hline MSc & $9(45)$ \\
\hline $\mathrm{PhD}$ & $6(30)$ \\
\hline MD & $5(25)$ \\
\hline
\end{tabular}

${ }^{\mathrm{a}}$ Values are expressed as No. (\%).

- Qualitative step:

- Qualitative expert interviews;

- Conceptual model Categories;

- First step: expert opinion (using the questionnaire);

- Modified primary model;

- Second step: expert opinion (using the questionnaire);

- Prioritizing sub-criteria;

- Third step: expert opinion;

- Achieving the main category and sub-categories.

- Quantitative step:

- Fuzzy DEMATEL method;

- Prioritizing the factors;

\subsection{First Step}

First, we applied the Delphi method. The researcher explained the purpose of the research and how to answer the questionnaire to the group of experts, and after obtaining the consent, the questionnaire was emailed to them.

The second questionnaire had 32 questions assessing the experts' opinion about the content of criteria and subcriteria that affect the quality of care in limited surgery facilities based on the conceptual model. At this stage, the initial conceptual model was obtained from an interview with experts. The conceptual model was then presented to the experts' team members, along with a description of the sub-criterion. Then, the degree of experts' agreement with each indicator was obtained, and their suggestions and modifications were classified. The model was modified based on the experts' opinion, the questionnaire was sent to experts by email, and the conclusive mean indicated to what extent they agreed with each research criterion. 


\subsection{Second Step}

In this stage, the third questionnaire was prepared and sent to the members of the expert group along with the previous experts' points of view and the degree of its disagreement with the viewpoints of others. In the second phase, the expert team members again responded to the questions, considering the viewpoints of other members, and some modifications were made in the sub-criterion. This questionnaire had 21 questions assessing the experts' opinions about the main criteria and sub-criteria of the extracted conceptual model (Figure 1 and Table 2).

According to the views presented in the first step and their comparison with the results of this step, if the difference between the two steps was less than the threshold value (0.2), then the survey process was ceased. The experts' opinions reached unanimity in a criterion, and the disagreement in the first and second stages was lower than the threshold of 0.2, thus, the survey on this criterion was stopped. The criterion suggested that the mean experts' non-fuzzy opinion was $<8$ that was omitted from the conceptual model of research. The survey on the remaining criteria was done in the third stage.

\subsection{Third Step}

In this stage, while making necessary changes to the model criterion, a fourth questionnaire (including three questions) was prepared and sent to the experts along with their previous viewpoints and the level of its difference with the mean value of other experts' opinions (Table 2 ).

To compare between criteria, five verbal expressions were used. The linguistic options, their definite numbers, and also triangular fuzzy numbers were as follows:

Very large impact (definite numbers $=4):(1,1,0.75)$;

Large impact (definite numbers $=3):(1,0.75,0.5)$;

Low impact (definite numbers $=2):(0.75,0.5,0.25)$;

Very low impact (definite numbers $=1):(0.5,0.25,0)$;

No effect (definite numbers $=0):(0.25,0,0)$.

DEMATEL, a research methodology, takes advantage of expert judgment in extracting a system's criterion and its systematic structuring by applying the principles of graph theory together with the reciprocal impact and influence of the above elements so that the severity of the effects of these interactions and their significance are specified as numerical scores. Five verbal expressions were used to compare the criteria with each other, and the opinions of eight experts were used to evaluate the criteria and pool the experts' opinions $(17,18)$.

In multiple-criteria decision-making (MCDM) methods, the analytic network process (ANP) is used to overcome the problems of interdependence and feedback between criteria or alternatives. The fuzzy ANP method was used to determine the importance and weight of each factor. In this research, we solved the fuzzy ANP model using the DEMATEL method based on the general relations matrix showing the degree of criterion impact and influence. Therefore, in this section, the general relations matrix of the DEMATEL was first normalized, and the weighted fuzzy supermatrix was obtained. Finally, the initial model was designed (19). Data were analyzed using Excel software 2013.

\section{Results}

The results showed the main content and sub-criteria of accreditation standards for limited surgery facilities, and the components affecting limited surgery centers were identified using the DEMATEL method (20).

The conceptual model is shown in Figure 1.

\subsection{First-Stage}

For this purpose, the primary model was corrected, as shown in Figure 2. The results of these calculations are given in Table 2 .

\subsection{Second Stage}

The results are presented in Table 2.

\subsection{Third Stage}

Regarding Table 2, the experts' disagreement in the second and third stages was less than the threshold of 0.2 , thus; the survey stopped at this stage.

The dimensions and components (criteria) are coded as bellow:

A) Dimensions

Safety management (C1), clinical care (C2), and management and leadership (C3).

B) Components (Criteria)

Prevention and management of common surgical complications (C11), prevention and control of infection (C12), immediate and emergency care (C13), surgical and anesthetic care (C21), continues care after surgery (C22), safe discharge, and follow-up of the patient (C23), quality management and patient safety (C31), human resource management (HRM) (C32), physical structure, facilities, and safe equipment (C33), and respect for patient rights (C34).

Then, the opinions of eight experts were used to assess criteria, and the experts' opinions were subsequently pooled.

To normalize, first, the sum of all rows and columns was calculated. We form the largest number in the row and column of $\mathrm{k}$, and then all values of the triangular fuzzy 


\section{Accreditation dimensions of limited surgery facilities}

\begin{tabular}{|c|c|c|}
\hline Safety management & Clinical care & $\begin{array}{l}\text { Management and } \\
\text { leadership }\end{array}$ \\
\hline $\begin{array}{l}\text { Management of common } \\
\text { surgical complications }\end{array}$ & $\begin{array}{c}\text { Safe discharge and follow-up } \\
\text { of patient }\end{array}$ & Partient rights and facilities \\
\hline $\begin{array}{c}\text { Safety management of } \\
\text { patient }\end{array}$ & Access to continued care & $\begin{array}{c}\text { Medical equipment } \\
\text { management Environmental }\end{array}$ \\
\hline $\begin{array}{l}\text { Infection prevention and } \\
\text { control }\end{array}$ & $\begin{array}{c}\text { Surgical and anesthetic care } \\
\text { General clinical care }\end{array}$ & $\begin{array}{l}\text { health and waste } \\
\text { management }\end{array}$ \\
\hline Acute and emergency care & Patient training & Human resource management \\
\hline $\begin{array}{l}\text { Assessment of general } \\
\text { conditions, etc. }\end{array}$ & $\begin{array}{c}\text { Clinical information } \\
\text { management }\end{array}$ & $\begin{array}{c}\text { Physical structure } \\
\text { Safety facilities }\end{array}$ \\
\hline Paraclinic management & & \\
\hline
\end{tabular}

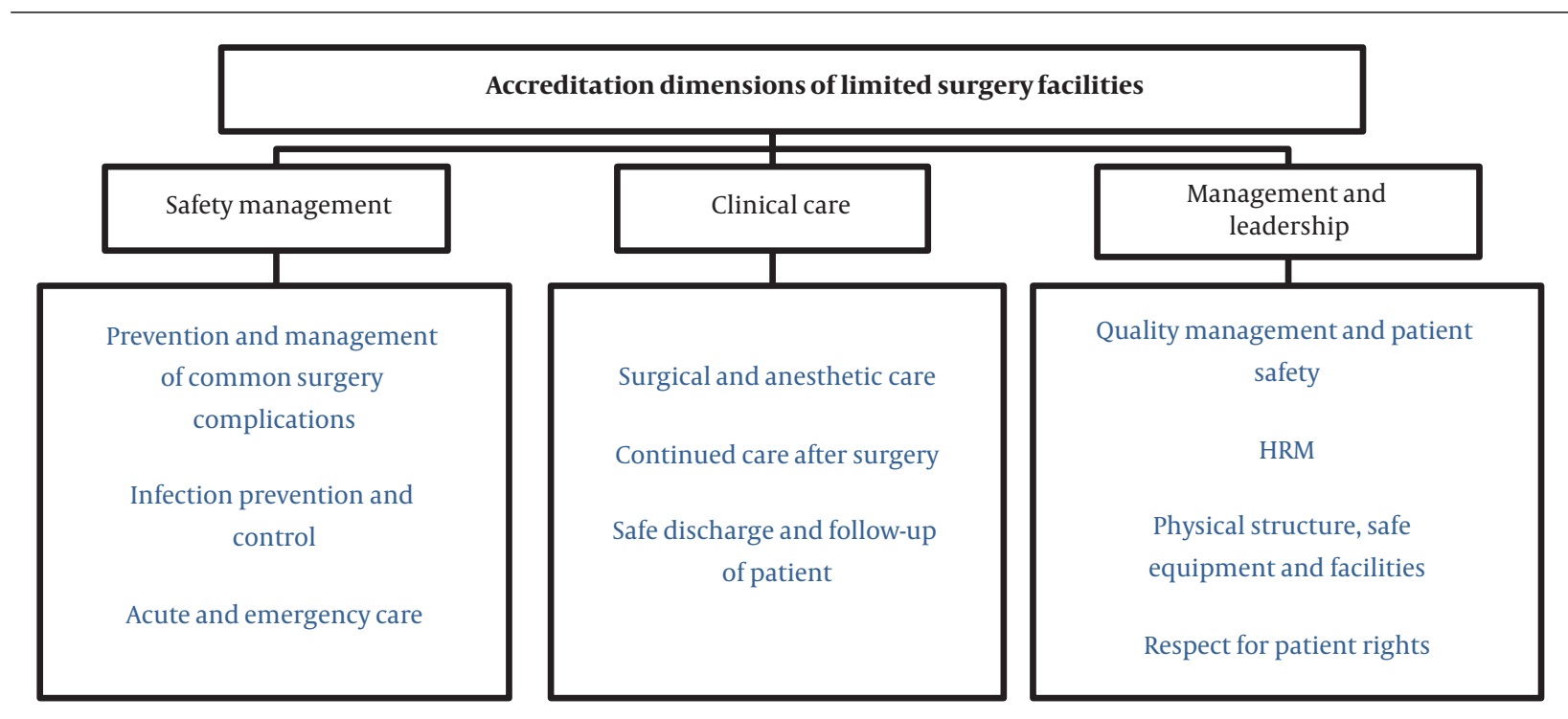

Figure 2. The modified primary model 


\begin{tabular}{|c|c|c|c|c|c|c|c|c|c|c|c|c|}
\hline Survey Stage & Component & Row & $\begin{array}{l}\text { Linguistic Value } \\
\text { Numerical Value } \\
\text { Sub-Criteria Fuzzy Value }\end{array}$ & $\begin{array}{c}\text { Very } \\
\text { High } \\
9 \\
(9,10,7)\end{array}$ & $\begin{array}{c}\text { High } \\
7 \\
7 \\
(7,9,5)\end{array}$ & $\begin{array}{c}\text { Moderate } \\
\qquad \begin{array}{c}5 \\
(7,3,5)\end{array}\end{array}$ & $\begin{array}{c}\text { Low } \\
3 \\
(5,1,0)\end{array}$ & $\begin{array}{l}\text { Very Low } \\
\qquad \begin{array}{c}1 \\
3,1,0)\end{array}\end{array}$ & Max & Mod & Min & $\begin{array}{l}\text { Non- } \\
\text { Fuzzy } \\
\text { Mean }\end{array}$ \\
\hline \multirow{16}{*}{$\begin{array}{l}\text { First surv ey } \\
\text { stage }\end{array}$} & \multirow{5}{*}{$\begin{array}{c}\text { Safety } \\
\text { management }\end{array}$} & 1 & $\begin{array}{l}\text { Prevention and management } \\
\text { of the common surgical } \\
\text { complications }\end{array}$ & 17 & 2 & 1 & 0 & 0 & 9.75 & 8.6 & 6.6 & 8.46 \\
\hline & & 2 & $\begin{array}{l}\text { Infection control and } \\
\text { prevention }\end{array}$ & 18 & 1 & 1 & 0 & 0 & 9.8 & 8.7 & 6.7 & 8.55 \\
\hline & & 3 & $\begin{array}{l}\text { Evaluation of the general } \\
\text { conditions, etc. }\end{array}$ & 0 & 1 & 6 & 6 & 7 & 5.1 & 3.1 & 1.45 & 3.16 \\
\hline & & 4 & Paraclinic management & 0 & 0 & 10 & 7 & 3 & 5.7 & 3.7 & 1.85 & 3.73 \\
\hline & & 5 & Acute and emergency care & 15 & 3 & 2 & 0 & 0 & 9.55 & 8.3 & 6.3 & 8.18 \\
\hline & \multirow{6}{*}{ Clinical care } & 6 & Surgical and anesthesia care & 13 & 4 & 3 & 0 & 0 & 9.35 & 8 & 6 & 7.89 \\
\hline & & 7 & Continuing care after surgery & 13 & 6 & 1 & 0 & 0 & 9.55 & 8.2 & 6.2 & 8.09 \\
\hline & & 8 & $\begin{array}{l}\text { Safe discharge and patient } \\
\text { follow-up }\end{array}$ & 17 & 2 & 1 & 0 & 0 & 9.75 & 8.6 & 6.6 & 8.46 \\
\hline & & 9 & General medical care & 5 & 5 & 9 & 1 & 0 & 8.15 & 6.4 & 4.4 & 6.36 \\
\hline & & 10 & Patient training & 5 & 6 & 8 & 1 & 0 & 8.25 & 6.5 & 4.5 & 6.46 \\
\hline & & 11 & $\begin{array}{l}\text { Health information } \\
\text { management }\end{array}$ & 10 & 4 & 5 & 1 & 0 & 8.8 & 7.3 & 5.3 & 7.22 \\
\hline & \multirow{5}{*}{$\begin{array}{l}\text { Management } \\
\text { and } \\
\text { leadership }\end{array}$} & 12 & $\begin{array}{l}\text { Quality management and } \\
\text { patient safety }\end{array}$ & 12 & 5 & 2 & 1 & 0 & 9.2 & 7.8 & 5.8 & 7.7 \\
\hline & & 13 & $\begin{array}{l}\text { Environmental health and } \\
\text { waste management }\end{array}$ & 0 & 0 & 5 & 5 & 10 & 4.5 & 2.5 & 1 & 2.58 \\
\hline & & 14 & $\begin{array}{l}\text { Human resource } \\
\text { management }\end{array}$ & 14 & 4 & 2 & 0 & 0 & 9.5 & 8.2 & 6.2 & 8.08 \\
\hline & & 15 & $\begin{array}{l}\text { Physical structure, facilities, } \\
\text { and safe equipment }\end{array}$ & 17 & 1 & 2 & 0 & 0 & 9.65 & 8.5 & 6.5 & 8.36 \\
\hline & & 16 & Respect for patient rights & 12 & 7 & 1 & 0 & 0 & 9.5 & 8.1 & 6.1 & 8 \\
\hline & \multirow{4}{*}{$\begin{array}{c}\text { Safety } \\
\text { management }\end{array}$} & \multirow{2}{*}{1} & \multirow{2}{*}{$\begin{array}{l}\text { Prevention and management } \\
\text { of the common surgical } \\
\text { complications }\end{array}$} & \multirow{2}{*}{18} & \multirow{2}{*}{2} & \multirow{2}{*}{0} & \multirow{2}{*}{0} & \multirow{2}{*}{0} & \multirow{2}{*}{9.9} & \multirow{2}{*}{8.8} & \multirow{2}{*}{6.8} & $\begin{array}{c}\text { Defuzzied } \\
\text { mean of } \\
\text { expert } \\
\text { opinion }\end{array}$ \\
\hline & & & & & & & & & & & & 8.65 \\
\hline & & 4 & Paraclinic management & 0 & 0 & 10 & 8 & 2 & 5.8 & 3.8 & 1.9 & 3.82 \\
\hline & & 5 & Acute and emergency care & 14 & 5 & 1 & 0 & 0 & 9.6 & 8.3 & 6.3 & 8.18 \\
\hline & \multirow{6}{*}{ Clinical care } & 6 & Surgical and anesthesia care & 17 & 2 & 1 & 0 & 0 & 9.75 & 8.6 & 6.6 & 8.46 \\
\hline & & 7 & Continuing care after surgery & 14 & 6 & 0 & 0 & 0 & 9.7 & 8.4 & 6.4 & 8.28 \\
\hline & & 8 & $\begin{array}{l}\text { Safe discharge and patient } \\
\text { follow-up }\end{array}$ & 17 & 3 & 0 & 0 & 0 & 9.85 & 8.7 & 6.7 & 8.56 \\
\hline & & 9 & General medical care & 2 & 10 & 6 & 2 & 0 & 8.1 & 6.2 & 4.2 & 6.18 \\
\hline & & 10 & Patient training & 5 & 6 & 9 & 0 & 0 & 8.35 & 6.6 & 4.6 & 6.56 \\
\hline & & 11 & $\begin{array}{l}\text { Health information } \\
\text { management }\end{array}$ & 10 & 5 & 4 & 1 & 0 & 8.9 & 7.4 & 5.4 & 7.32 \\
\hline & \multirow{5}{*}{$\begin{array}{l}\text { Management } \\
\text { and } \\
\text { leadership }\end{array}$} & 12 & $\begin{array}{l}\text { Quality management and } \\
\text { patient safety }\end{array}$ & 13 & 5 & 2 & 0 & 0 & 9.45 & 8.1 & 6.1 & 7.99 \\
\hline & & 13 & $\begin{array}{l}\text { Environmental health and } \\
\text { waste management }\end{array}$ & 0 & 0 & 5 & 5 & 10 & 4.5 & 2.5 & 1 & 2.58 \\
\hline & & 14 & $\begin{array}{l}\text { Human resource } \\
\text { management }\end{array}$ & 15 & 4 & 1 & 0 & 0 & 9.65 & 8.4 & 6.4 & 8.28 \\
\hline & & 15 & $\begin{array}{l}\text { Physical structure, facilities, } \\
\text { and safe equipment }\end{array}$ & 17 & 2 & 1 & 0 & 0 & 9.75 & 8.6 & 6.6 & 8.46 \\
\hline & & 16 & Respect for patient rights & 13 & 7 & 0 & 0 & 0 & 9.65 & 8.3 & 6.3 & 8.19 \\
\hline $\begin{array}{l}\text { Second } \\
\text { survey stage }\end{array}$ & \multirow{2}{*}{ Clinical care } & \multirow[b]{2}{*}{6} & \multirow{2}{*}{ Clinical and anesthesia care } & \multirow{2}{*}{15} & \multirow[b]{2}{*}{4} & \multirow[b]{2}{*}{1} & & & & & & $\begin{array}{c}\text { Defuzzied } \\
\text { mean of } \\
\text { expert } \\
\text { opinion }\end{array}$ \\
\hline \multirow[b]{2}{*}{$\begin{array}{l}\text { Third survey } \\
\text { stage }\end{array}$} & & & & & & & 0 & 0 & 9.65 & 8.4 & 6.4 & 8.28 \\
\hline & $\begin{array}{l}\text { Management } \\
\text { and } \\
\text { leadership }\end{array}$ & 12 & $\begin{array}{l}\text { Management of the quality } \\
\text { and patient safety }\end{array}$ & 13 & 6 & 1 & 0 & 0 & 9.55 & 8.2 & 6.2 & 8.09 \\
\hline
\end{tabular}

numbers were multiplied by the inverse of $\mathrm{k}$ to normalize the matrix.

To calculate the full correlation matrix, the identity ma- trix (I) was first formed. Then, we subtracted the intensity matrix from the normal matrix and inverted the resulting matrix. Finally, the normal matrix was multiplied by the 
inverse matrix.

Table 3 shows the pooled direct fuzzy matrix of the main criterion, the matrix of normalized relations between the main criteria, and the general fuzzy relations matrix of the main criterion.

The next step was obtaining the sum of rows and columns of $T$ matrix. The sum of rows and columns was determined, and then the significance of $\tilde{D}_{i}+\tilde{R}_{i}$ indices, as well as the relationship between the criteria $\left(\tilde{D}_{i}-\tilde{R}_{i}\right)$ were obtained. If $\tilde{D}_{i}-\tilde{R}_{i}>0$, then the relevant criterion is effective and if $\tilde{D}_{i}-\tilde{R}_{i}<0$, it is influenced. In the next step, the fuzzy numbers $\tilde{D}_{i}+\tilde{R}_{i}$ and $\tilde{D}_{i}-\tilde{R}_{i}$ from the previous step were defuzzed.

$B=\frac{\left(a_{1}+a_{3}+a_{2}\right)}{3}$

The defuzzied $\mathrm{B}$ is the $\tilde{A}=\left(\mathrm{a}_{1}, \mathrm{a}_{2}, \mathrm{a}_{3}\right)$ number. The values of impact $(\tilde{D})$, influence $(\tilde{R})$, importance $(\tilde{D}+\tilde{R})$, and net impact and influence $(\tilde{D}-\tilde{R})$ for the main criterion, and also those of the sub-criterion are presented in Table 4 .

According to Table 4 , when $\tilde{R}-\tilde{D}$ value is positive for an index, it can be effective and when $\tilde{R}-\tilde{D}$ is negative, the index can be influenced; therefore, among the main criteria, "management and leadership" with net impact/influence of 1.803 was the most effective, and "safety management" with net impact/influence equal to -1.13 was the most influenced factor. Overall, positive $\tilde{R}-\tilde{D}$ value is a measure of cause, and negative $\tilde{R}-\tilde{D}$ was the effect criterion. Table 4 also presents the values for sub-criteria.

The general relations fuzzy matrix is used to determine the network relation map (NRM). In the NRM for the criterion and sub-criterion, the significance $\left(\tilde{D}_{i}+\tilde{R}_{i}\right)$ as well as impact and influence $\left(\tilde{D}_{i}-\tilde{R}_{i}\right)$ are specified between the criteria. Among the main criteria, the "management and leadership" factor affects "clinical care" and "safety management". Also, "clinical care" had an impact on "safety management" and was influenced by the "management and leadership" factor. Finally, "safety management" was the most influenced factor that was affected by "management and leadership" and "clinical care".

\subsection{Results of the Network Analysis Process}

Afterward, the significance and weight of each factor must be determined to prioritize the criterion based on weight and reach the desired goals. Since there is a relationship between the criteria, the fuzzy ANP method is used to weight the criterion. In this research, we attempted to solve the fuzzy ANP based on the general relations matrix that shows the degree of impact and influence of criterion. The fuzzy DEMATL method was used to solve the fuzzy ANP model. In this section, we first normalized the DEMATEL general relations matrix to obtain a fuzzy matrix of weighted supermatrix. It is worth noting that the unweighted matrix is the same as the general relations matrix. Finally, the weight of criterion and sub-criterion was specified and determined by obtaining and defuzzying the limited supermatrix.

According to Table 4, the highest weight was related to the "safe patient discharge and follow-up" factor, which gained the first priority. The second to sixth priorities were "Prevention and management of common surgical complications", "infection prevention and control", "continuing post-surgical care”, "acute and emergency care”, and "surgical and anesthesia care", respectively, which accounted for $43.3 \%$ of the total weight of sub-criterion, indicating the high significance of this sub-criterion.

The main criterion priority of safety management, clinical care, and management and leadership were $42 \%, 40 \%$, and $18 \%$, respectively. Figure 3 shows the final sub-criterion priority graph using the Fuzzy ANP method.

\section{Discussion}

The limited and ambulatory surgery facility is the most important cornerstones of the health system in any country, and it would not be possible to reform the health system without addressing these facilities and improving their performance. Analysis of the performance of limited surgery facilities requires a different tool considering all the factors affecting patient safety and treatment $(16,21)$. Due to a large number of limited and ambulatory surgical services in these facilities, the existing evaluation package is not sufficiently comprehensive. According to the findings of the present study, patient safety management has the most significant impact on the performance of limited surgery centers, which has not been explained in the current package of The Ministry of Health and Medical Education of Iran. Furthermore, based on the results of this research, clinical care has less impact, and finally, management and leadership have the least impact among the core components. According to Figure 3, patients' departure at the time of discharge, prevention and management of common surgical complications, as well as infection control, have the highest priority, which means that the implementation of these standards has the most significant impact on the performance of limited surgery facilities. It can be stated that the formulation of standards for limited surgery facilities in light of the above findings should focus more on the factors affecting the safety management, especially patient safety in pre-, intra- and postanesthesia phases and surgery care processes as well as safe discharge, prevention, and control of common surgical complications. Based on the findings of this study, it 
Table 3. Pooled Direct Fuzzy Matrix of Main Criterion, Matrix of Normalized Relations Between Main Criteria and General fuzzy Relations Matrix of Main Criterion

Pooled direct fuzzy matrix of the main criterion

C1

L

M

U

C2

$\mathrm{L}-0.6$

$0.6-0$

0.65

M

0.85

0

0.9

0.95

0.6

0.85

0.75

1

C3

L 0.1

0.35

0.15

0

M

0.4

0

U

0.6

0.65

0

Matrix of normalized relations between main criteria

C1

L

M

0

0.556

0.444

U

0.541

0.459

C2

o

0.5

0.5

L

0.444

0.481

0.459

0.475

0.486

U

.

C3

$\begin{array}{ll}\mathrm{L} & 0.074\end{array}$

M

0.189

$\mathrm{U}$

0.3

0

0

0.5

General fuzzy relations matrix of the main criterion

\begin{tabular}{|c|c|c|c|}
\hline \multicolumn{4}{|l|}{$\mathrm{C} 1$} \\
\hline $\mathrm{L}$ & 0.515 & 0.968 & 1.139 \\
\hline M & 0.928 & 1.379 & 1.556 \\
\hline $\mathrm{U}$ & 1.812 & 2.225 & 2.518 \\
\hline \multicolumn{4}{|l|}{$\mathrm{C} 2$} \\
\hline $\mathrm{L}$ & 0.768 & 0.548 & 1.087 \\
\hline M & 1.188 & 0.967 & 1.503 \\
\hline $\mathrm{U}$ & 2.099 & 1.854 & 2.476 \\
\hline \multicolumn{4}{|l|}{ C3 } \\
\hline $\mathrm{L}$ & 0.198 & 0.244 & 0.205 \\
\hline M & 0.622 & 0.686 & 0.619 \\
\hline U & 1.526 & 1.595 & 1.56 \\
\hline
\end{tabular}

Health Scope. 2020; 9(3):e99351. 


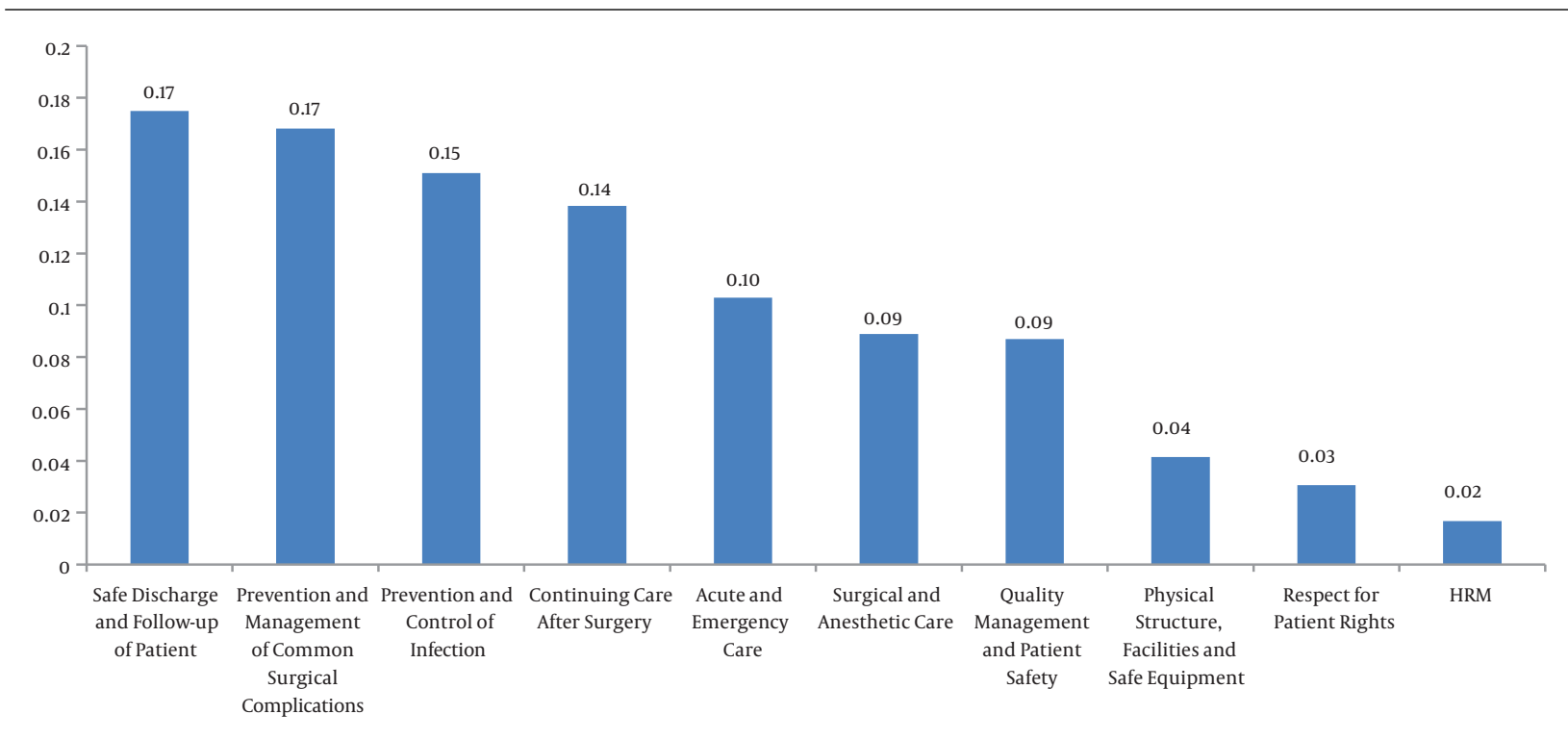

Figure 3. Final priority graph of the sub-criterion (HRM: human resource management)

can be concluded that these facilities should further consider the issues related to surgical complications and patient safety, and also they must focus on the full implementation of these standards to improve the quality of their services.

Chatterjee et al. (4) reported that quality improvement and patient safety due to the accreditation are the major priority for decision-makers and the public in today's dynamic healthcare environment. Quality improvement, risk management, patient safety, improved efficiency, and accountability are the main domains of the organizations that participate in accreditation based on the report published by the Accreditation Canada in 2013 (22). Pearcy and Terranova (23) also highlighted that patient safety is the most important issue in the accreditation of outpatient units, which is consistent with the present study. Also, the study of accreditation models for limited surgical centers worldwide, e.g., JCI (24), Accreditation Canada International (ACI) (25), and the American Association for Accreditation of Ambulatory Surgery Facilities (AAAASF ((26), revealed that the patient safety has top priority in the designing the model of accreditation, which is consistent with our results.

In formulating standards regarding the quality and safety of care, the individual and especially the family should be considered as the basis, and the formulation of patient-centered standards is a top priority (27). Although patient rights is an important concept, it gained a little weight and was considered as the ninth factor in the designed model of the present study, and it should be taken into consideration in the formulation of standards along with the patient's family rights.

Clinical care standards as another part of the designed model can include surgical and anesthetic care, continuing care after surgery, safe discharge, and follow-up of the patient. In the AAAASF accreditation model, there has been a strong emphasis on effective operating room policies, safety, environmental management, safe drug management, information registration, and anesthesia service safety. This issue emphasizes the accreditation standards of the American Outpatient Accreditation Association on patient rights, center management, and leadership, quality of service provided, information registration, pharmaceutical services, safe and effective anesthesia and surgery, quality management, and promotion. It is consistent with most of the domains and dimensions obtained from the present study (28). Springer (29) also highlighted the areas of formulating standards and facilities, sterilization, equipment, recovery, safety, medicine, and data recording that are consistent with the results of the present study.

However, after obtaining statutory licenses, only 900 institutions known as hospitals have formulated accreditation models, and other medical institutions lack such accredited models. By the end of 2018, more than 300 limited surgery and ambulatory service centers have been established. Thus, with an average of at least ten surgeries per day at a single center, more than 770,000 people undergo surgery at these centers, making up a large portion of the nation's 7,000,000 annual operations. Since the time-limited surgical centers have been established in 


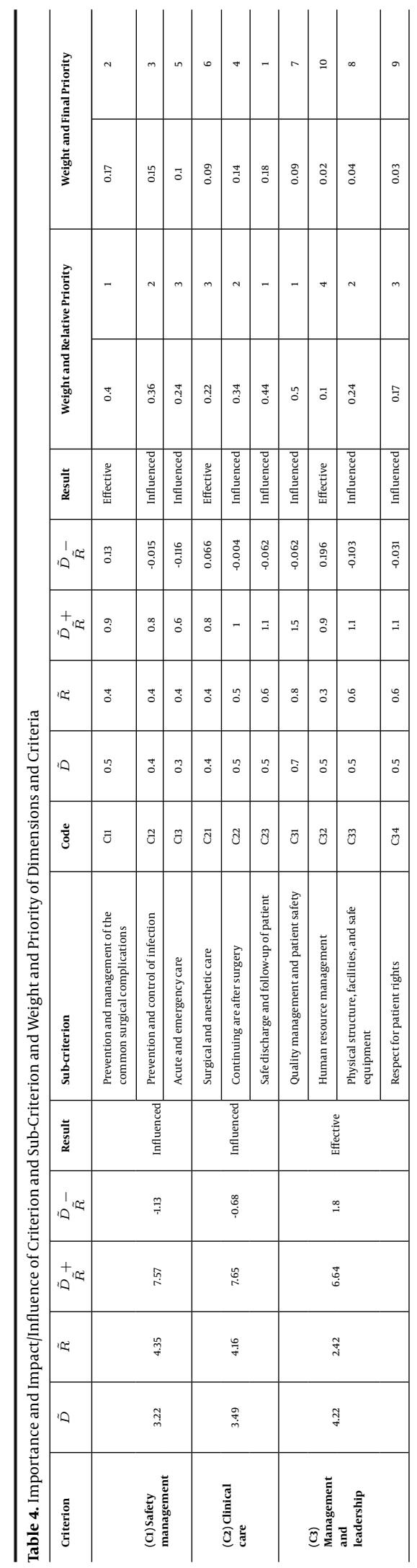

Iran, there have been several unexpected deaths and adverse events due to non-compliance with safety principles, lack of quality standards, and inadequate regulatory supervision $(27,30)$. Moreover, given the priority of clinical care in management and leadership, according to the findings of this study, there should be more focus of these standards on treatment and continuity of care and less impact of management and leadership proportionate to specific features of these centers.

\subsection{Conclusions}

Since the inception of limited surgical centers in Iran, there have been several unexpected deaths and adverse events following failure to adhere to safety principles, lack of quality standards, and weak oversight of surveillance systems $(27,30)$. Also, 110,000 of the medial institutions are active in Iran that should offer services based on quality standards and meet certain criteria. Considering the preparation of standards of these facilities, an emphasis on the dimensions of safety and management of surgical complications will have the greatest impact on the performance improvement of these centers. It is recommended to formulate the accreditation standards of limited surgery centers with a local approach using the results of this study. According to our findings, the formulation of the standards of the limited surgical centers should be more focused on the safety and management of surgical complications.

\section{Acknowledgments}

We are grateful to the study participants for their time and viewpoints.

\section{Footnotes}

Authors' Contribution: Study concept and design: NA, IMA, and SH. Analysis and interpretation of data: NA and SH. Drafting of the manuscript: NA. Critical revision of the manuscript for important intellectual content: NA, IMA, SH, and SV. Statistical analysis: NA. Study supervision: IMA, SH and SV.

Conflict of Interests: No potential conflict of interest was reported by the authors.

Ethical Approval: All rights are reserved for the Islamic Azad University of Medical Sciences. This study has been extracted from a doctoral dissertation that was approved in January 2017. Ethical approval for this study will be obtained from the research Ethics Committee of the Islamic Azad University of Medical Sciences. 
Funding/Support: No grants were involved in supporting this work

Informed Consent: Informed consent was obtained from all participants before the study, and individual identities were not used during data analysis.

\section{References}

1. Tabrizi JS, Gharibi F, Pirahary S. Developing of National Accreditation Model for Rural Health Centers in Iran Health System. Iranian Journal of Public Health. 2013;42(12):1438-45.

2. Shams A, Yarmohammadian $M H$, Hassanzadeh A, Hayati Abbarik $H$. Determining the Criteria of Customer-Orientation in Education: Viewpoints of Students at Isfahan University of Medical Sciences, Iran. Health Information Management. 2011;8(22):1086-96.

3. Sekimoto M, Imanaka Y, Kobayashi H, Okubo T, Kizu J, Kobuse H, et al. Impact of hospital accreditation on infection control programs in teaching hospitals in Japan. American journal of infection control. 2008;36(3):212-9.

4. Chatterjee A, Awasthi P, Basukala S. Impact of Accreditation on the Quality of Healthcare Services: A Systematic Review of the Literature. International Journal of Scientific Research. 2016;5(7).

5. Vanoli M, Traisci G, Franchini A, Benetti G, Serra P, Monti MA. A program of professional accreditation of hospital wards by the Italian Society of Internal Medicine (SIMI): self-versus peer-evaluation. Internal and emergency medicine. 2012;7(1):27-32.

6. El-Jardali F, Jamal D, Dimassi H, Ammar W, Tchaghchaghian V. The impact of hospital accreditation on quality of care: perception of Lebanese nurses. International journal for quality in health care. 2008;20(5):363-71.

7. Greenfield D, Braithwaite J. Health sector accreditation research: a systematic review. International journal for quality in health care. 2008;20(3):172-83.

8. Rooney AL, Van Ostenberg PR. Licensure, accreditation, and certification approaches to health services quality. Center for Human Services, Quality Assurance Project; 1999.

9. Salmon JW, Heavens J, Lombard C, Tavrow P. The impact of accreditation on the quality of hospital care: KwaZulu-Natal province Republic of South Africa. Operations Research Results. 2003.

10. Avia I, Hariyati RTS. Impact of hospital accreditation on quality of care: A literature review. Enfermeria clinica. 2019;29:315-20.

11. Greenfield D, Lawrence SA, Kellner A, Townsend K, Wilkinson A. Health service accreditation stimulating change in clinical care and human resource management processes: A study of 311 Australian hospitals. Health policy. 2019;123(7):661-5.

12. Behera SK, Smith SN, Tacy TA. Impact of accreditation on quality in echocardiograms: a quantitative approach. Journal of the American Society of Echocardiography. 2017;30(9):913-22.
13. Nicklin W, Fortune T, van Ostenberg P, O'Connor E, McCauley N. Leveraging the full value and impact of accreditation. International Journal for Quality in Health Care. 2017;29(2):310-2.

14. Menachemi N, Chukmaitov A, Brown LS, Saunders C, Brooks RG. Quality of care in accredited and nonaccredited ambulatory surgical centers. The joint commission journal on quality and Patient Safety. 2008;34(9):546-51.

15. Ministry of health and medical education. MOHME, regulation on establishment of limited and ambulatory surgery centers. 1986.

16. Emami Razavi H, Mohaghegh M. Hospital accreditation standards. Seda Publication, Tehran. 2008.

17. Jeng DJ, Tzeng G. Social influence on the use of clinical decision support systems: revisiting the unified theory of acceptance and use of technology by the fuzzy DEMATEL technique. Computers \& Industrial Engineering. 2012;62(3):819-28.

18. Wu H, Shieh J, Li Y, Chen H. A combination of AHP and DEMATEL in evaluating the criteria of employment service outreach program personnel. Information Technology Journal. 2010;9(3):569-75.

19. Cheng C, Lin Y. Evaluating the best main battle tank using fuzzy decision theory with linguistic criteria evaluation. European journal of operational research. 2002;142(1):174-86.

20. Saaty TL. Decision making with the analytic hierarchy process. International journal of services sciences. 2008;1(1):83-98.

21. Telem DA, Talamini M, Altieri M, Yang J, Zhang Q, Pryor AD. The effect of national hospital accreditation in bariatric surgery on perioperative outcomes and long-term mortality. Surgery for Obesity and Related Diseases. 2015;11(4):749-57.

22. [No author listed]. The Value and Impact of Health Care Accreditation: A Literature Review. Canada: Accreditation Canada; 2013.

23. Pearcy J, Terranova T. Mandate for accreditation in plastic surgery ambulatory/outpatient clinics. Clinics in plastic surgery. 2013;40(3):48992

24. JCI. Accreditation Standards for Ambulatory Care. 3rd ed. America: Joint Commission International; 2015.

25. ACI. Accreditation Canada International (ACI). Independent Medical/Surgical Facilities Standards. Canada: Accreditation Canada; 2016.

26. American Association for Accreditation of Ambulatory Surgery Facilities Inc. Regular Standards and Checklist for Accreditation of Ambulatory Surgery Facilities. 2017.

27. Ahmadi MARYAM, Khoshgam M, Mohammadpoor A. Comparative study of the Ministry of Health standards for hospitals with Joint Commission International hospital accreditation standards. Hakim Research Journal. 2008;10(4):45-52.

28. Urman RD, Philip BK. Accreditation of ambulatory facilities. Anesthe siology clinics. 2014;32(2):551-7.

29. Springer R. A practical guide to achieving AAAASF accreditation. Plas tic Surgical Nursing. 2002;22(3):115-36.

30. Moe JK, Lonowski LR, Yancer DA. Combining a clinical ladder and performance appraisal system as a reward strategy: the EXCEL clinical ladder program. Seminars for nurse managers. 1994. p. 175-82. 